diagrams, \&c., were exhibited, showing the meteorological conditions prevailing over the various oceans of the globe. The advance made in synoptic meteorology over the North Atlantic was clearly shown by comparing Leverrier's charts (1864) with the daily synchronous weather charts just published by the Meteorological Council. The specimens exhibited of the latter were (I) August I-6, showing the meteorological conditions in the summer; (2) February 9-I4, showing the conditions in the winter; and (3) February 24 to March 4, showing the conditions in early spring, and the persistence of the European anticyclone, producing cold dry winds over England. The Meteorological Council also exhibited a set of large charts showing the mean temperature of the sea surface round the coasts of the British Isles for each month. Dr. Mill had several interesting diagrams showing the distribution of temperature in a section of the Clyde sea area at seven periods from April 1886 to February 1887. Mr. Abercromby exhibited forty-six photographs and diagrams of clouds taken in various parts of the world ; and Mr. Dyason showed a number of coloured drawings of clouds, \&c. The Astronomer Royal sent the photographic registers of magnetic declination and horizontal force at the Royal Observatory, Greenwich, showing the earthquake shock which occurred on the morning of February 23.

The most interesting of the new instruments was the Watkin aneroid with open scale, by Mr. Hicks. Instead of the usual one-circle of figures, the scale of this instrument consists of a spiral of three complete turns. On the aneroid being put under an air-pump or taken up a mountain, the point of the index is gradually drawn toreards the centre, so that it follows the decreasing spiral scale; but when the index moves in the opposite direction, the point moves away from the centre, thus following the increasing spiral. This is effected by the index-hand being made to slide in and out, so that one end may advance or recede from the centre, and thus follow the spiral scale. Attached to the spindle is a cross-piece, in which the index slides, and a hollow drum fixed to the dial-plate has a flexible chain or cord wound round it, the ends being fastened on the projecting pins riveted to the index. Consequently, if the spindle and the piece attached to it are revolved, one portion of the chain or cord winds off the drum, the other is wound on to the same extent, and the index is caused to slide through the cross-piece, the direction of motion being controlled by the direction in which the spindle is revolved.

MM. Richard Frères sent specimens of their selfrecording thermometer, hygrometer, dry and wet bulb thermometers, and rain-gauge.

\section{GEOGRAPHY AT THE UNIVERSITIES}

$A^{T}$ last, after years of apparently fruitless labour, the Royal Geographical Society have been eminently successful in persuading almost simultaneously the two great English Universities to recognise geography as a University study, and to make definite provision for teaching it. In pursuance of a proposal made by the President and Council of the Royal Geographical Society to the Vice-Chancellors of the two Universities, and of the replies thereto, a deputation of a few members of their Council visited Oxford and Cambridge in turns, to meet delegates appointed by those Universities, in order to explain their proposal more fully, and to discuss any modifications that might be suggested. The main features of the proposal were, that the Royal Geographical Society offered to give $150 /$. annually to each University if they would establish a Lectureship or Readership in Geography, giving the Lecturer an adequate University status, and contributing, on their part, an equal sum, so as to raise the stipend of each Lectureship to $300 \%$. They also offered to give the two Universities a Scholarship or Exhibition of $100 l$. in alternate years for geographical students. The Royal Geographical Society was to be represented on the Board that selected the Examiners, and on that which adjudged the Scholarship.

The meeting at Oxford with delegates from that University, including the present and past Vice-Chancellors, took place five weeks ago, at which the proposal was well discussed and favourably entertained, subject to the foreseen difficulty of finding adequate funds from the University resources ; nevertheless everything seemed in train for its being eventually carried out, though after a little delay, in the intended manner. An unexpected incident, however, gave a new and collateral impulse, and has hurried the Lectureship into existence at once. It happened that the Readership in Ancient History became vacant, and it seems to have occurred to those with whom the election of a successor rested, that as there was a great difficulty in finding funds for geography, and as a Professorship of Ancient History was already in existence, and, again, as ancient history was taught by most classical tutors, the Readership in Ancient History might be abolished without much loss, and one in geography might be with propriety established in its place. There was a nearly even division of opinion on the matter, but the vote for geography prevailed and carried the day, and the advertisement inviting candidates has already been published. So Oxford now takes an independent line, and accepts only the offer of the Scholarship.

The Cambridge meeting took place about three weeks ago. The proposal was carefully discussed, and modifications were asked for. At Cambridge, as at Oxford, the University funds are seriously embarrassed by engagements already entered into, chiefly connected with building operations; and there seemed no way, so narrow was the available surplus, of raising the whole of the annual amount of $150 l$. in a direct form, but only $50 \mathrm{O}$. of it However, it appeared that indirect means existed by which this nominal sum would indirectly and eventually be raised to even something more than the proposed amount, and an amendment specifying only $50 l$. was therefore provisionally accepted. After this had received the approval of the Council of the Royal Geographical Society, it was submitted to the Council of the University of Cambridge, and adopted by them in the terms of the following recommendation :- -

"That the approval of the Senate be given to the delivery in the University in the ensuing academical year of one or more courses of lectures on geography by lecturers selected by the Royal Geographical Society, that a teacher of geography be appointed by a Committee on which the Royal Geographical Society is represented, and that the Senate accept the proposal of the Royal Geographical Society to award in alternate years an Exhibition of $100 l$. or prizes of $50 l$. and $25 l$. That before the end of the Easter Term, I 888 , a University Lecturer in Geography be appointed, for a period of five years, at a stipend of $200 \%$. a year, of which sum $50 l$. is to be paid out of the common University fund and I5ol. by the Royal Geographical Society. The appointment of the Lecturer to be made by a joint Committee of the representatives of the Royal Geographical Society and of the Council of the Senate, subject to the confirmation of the Senate; the Lecturer to submit his scheme of lectures to the Committee of Management; and power is to be given to the Council of the Senate, with the concurrence of the Committee of Management, to cancel the appointment of the Lecturer at any time."

This recommendation has to be submitted to the Senate at the beginning of next term, but its ultimate acceptance is placed almost beyond doubt through the very favourable reception given to the proposals of the Royal Geographical Society by the Council of the University. 